\title{
A Study of Writing Proficiency in the Use of Discourse Markers in Iranian EFL Learners' Writing
}

Ozra Kookhaei,

M.A in TEFL, State Arak university, Iran

Majid Amerian,

P.H.D in TEFL, State Arak university, Iran

\section{Abstract}

The aim of this study was to investigate the use of discourse markers by Iranian EFL learners based on their writing proficiency. The study was conducted at Department of English Language and Literature in university of Arak. 29 participants, 6 males and 23 females, as an intact group, were required to write an essay on an argumentative topic without limit of words and without any instruction. Their writings were analyzed quantitatively using Fraser's (2004) taxonomy of Discourse Markers. The results showed that there is no statistically significant difference between the use of discourse markers and writing proficiency. It was also founded that participants employed a variety of discourse markers with some types used more frequently than others. Coordinate conjunction were the most frequently used, followed by elaborative markers and contrastive markers. Possible implications of the study for language pedagogy have been also discussed.

Keywords: Discourse markers; writing proficiency; Essay writing.

\section{Council for Innovative Research}

Peer Review Research Publishing System

Journal: Journal of Advances in Linguistics

Vol 2, No.2

editor@cirworld.com

www.cirworld.com, member.cirworld.com 


\section{Introduction}

Language is at the center of human life and thus is a vital instrument for the exchange of ideas, experiences, emotions, and attitudes. This social instrument is used by human beings to share their common world. Nowadays, with the advent and quickly spreading use of the Internet, bringing various concerns of the globe together in one large community, comprehensible written English of any kind is becoming vital to any modern person's array of social skills. Since English is recognized as one of the most widely-used languages in the world, intelligible written English is not only a critical business skill, but a generally-used social skill as well. Discourse markers are one of the elements of good and well-formed writing which is believed not only to help writers to write better but also to facilitate the reading process for readers.

Redeker (1990) divides discourse markers into two categories: those that mark ideational structure, such as connectives and temporal adverbials (e.g. and, meanwhile, or now) and those which mark pragmatic structure (e.g. oh, alright or well).

Schiffrin divided DMs into three types: the first includes DMs that have referential meaning such as: and, but and or which serve as cohesive devices that contribute to the coherence of discourse. The second type includes DMs which lack (referential) meaning, such as: oh and well. Such markers are independent of the sentential syntactic structure of discourse. They do not have a cohesive role similar to those of the first type, but affect discourse interpretation in the sense that they indicate relationships at the level of 'information state', i.e. markers of information management. The third type includes DMs that have referential meaning but are independent of the sentential structure such as $I$ mean and $y^{\prime} k n o w$. Although they have semantic meaning, such markers can be removed from the text structure without affecting the meaning or grammaticality of the text.

Both Schiffrin (1987) and Halliday and Hasan (1976) agree that DMs should be considered as linguistic devices that link adjacent unites of talk to make the whole discourse coherent. Schiffrin proposes that DMs play a cohesive role in the sense that they relate informational units in the present discourse with informational units in the prior discourse; this kind of coherence achieved by DMs is known as local coherence in Schiffrin's framework. It is local in the sense that DMs link two adjacent units in the text.

Schiffrin gives a detailed analysis of twelve DMs in English: and, but, or, so, well, then, now, because, oh, well, y'know and I mean. The data that Schiffrin used to analyze these DMs are based on her sociolinguistic corpus which is composed of tape-recorded interviews with ordinary speakers. The data consist of long transcribed speech units taken from these interviews.

Schiffrin maintains that DMs can function on different levels of discourse structure (linguistic or non-linguistic). They can operate on the 'ideational' (informational) structure in the sense that they indicate relations between ideas in discourse or in other words, they mark the organization of ideas in discourse. For instance, a DM such as but indicates that what follows it contrasts with what precedes it. They can also operate on the participation framework (discourse exchange and interaction) in the sense that they play a role in controlling the conversational labor between speakers and hearers as is the case with oh and well.

My discourse model has both non-linguistic structures (exchange and actions) and linguistic structures (ideational). Speaker and hearer are related to each other, and to their utterances, in a participation framework. Their knowledge and meta-knowledge about ideas is organized and managed in an information state. Local coherence in discourse is thus defined as the outcome of joint efforts from interactants to integrate knowledge, meaning, saying and doing.

(Schiffrin 1987:29)

Green (2006) describes discourse markers as little words or phrases which generally add nothing truth of the sentence they are part of; they, however, reflect an attitude of the speaker toward what is being said in the present utterance. According to Green (2006), there are two basic kinds of discourse particles: a) attitudinal discourse markers, such as well, uh, like, gosh, oh, OK, I mean, and you know, which indicate something about how the speaker feels about what is being said, or how one feels about how the addressee feels about what is being said, and structural discourse markers like the sentence initial particles Now, OK, And, But, which speakers use to indicate a structural boundary, and a hint of how what follows relates to what went before.

Based on above discussions, the following question is formulated:

\subsection{Research Question}

Q:Is there any significant difference in the use of DMs in writing of Iranian EFL learners and their writing proficiency?

\subsection{Research Hypothesis}

To answer the above question the following hypothesis made:

$\mathrm{H}$ :There are not any differences in the use of DMs in writing of Iranian EFL learners and their writing proficiency.

\section{Methodology}

\subsection{Research population:}


This study was conducted at Department of English Language and Literature in university of Arak. The data in this study were collected from 29 BA students who were 6 male and 23 female. The subjects were required to write an essay on an argumentative topic without limit of words.

Fig1: Number of subjects by their gender

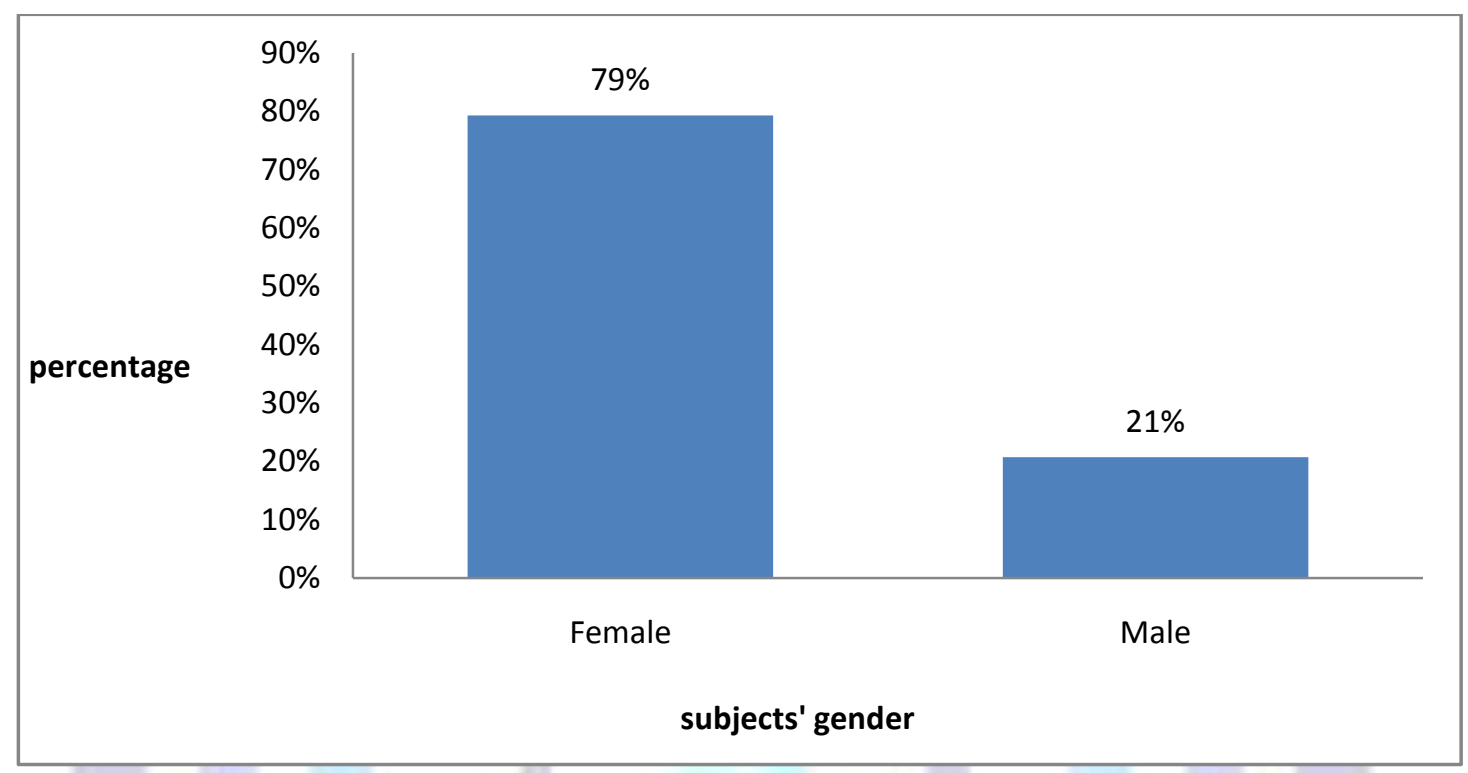

The above Fig1 shows the percentage of subject's gender. The percentage of female is $79 \%$ and male is $21 \%$.

\subsection{Procedures}

The subjects were asked to write an assay about the following topic "Do you agree or disagree with the following statement?" Parents are the best teachers". Preventing from research bias, the writing was assigned as a classroom task, and the subjects did not know the purpose of this experiment. Thus we could ensure the subjects would use DMs as usual. During and after writing they received no feedback. The experiment was conducted within one session class time. They received no instruction.

Ranking subjects based on their writing proficiency, 4 raters marked the writings independently. They asked to use analytic grading and the scale which used for this purpose "composition grading scale" (Bailey \&

Brown, 1984). The final marking was the result of dividing each rater's score by four. Then the 29 articles were examined whether discourse markers had been used in them and how many discourse markers had been used based on their writing proficiency.

\subsection{Identifying the writing proficiency of the subjects}

For measuring the writing proficiency of learners, the researcher preferred to use four raters. These raters scored the essays of learners anonymously. Then the average of these scores revealed the learner's final score and consequently we could rank the subjects based on their writing proficiency.

Because the scoring of composition or essay is highly subjective; with considering the factors that contribute to unreliability, the assessment can be reliable. So, establishment of a criterion is the first requirement. Moreover, using more than one rater-preferably 3 or 4 -in scoring each essay is requested.

\section{Result and Discussion}

In this part of study, the four raters rated essays based on Baily \& Brown (1984) composition grading scale. The scores of raters were averaged and considered as the essays final scores. Inter-rater reliability in rating the essays was obtained. For this purpose, we use Equal-length Spearman-Brown reliability formula and $r=0.7649$ which according to Farhady et al (1994) is high and acceptable. The averaged scores ranged from 42.5 to 79.5 . The final scores were ranked from highest to lowest. Then the differences between writing proficiency and the use of DMs calculated.

In the table below, the correlation between writing proficiency and different kinds of DMs were shown. As it is clear from the first row of the table, the $p$-value also calculated for different DMs (semantic and syntactic).

Table 1: The correlation between writing proficiency and different kinds of DMs 


\begin{tabular}{|c|c|c|c|c|c|c|c|c|c|c|}
\hline \multicolumn{2}{|c|}{} & $\begin{array}{c}\text { Contras } \\
\text { tive } \\
\text { Marker } \\
\text { s }\end{array}$ & $\begin{array}{c}\text { Elabora } \\
\text { tive } \\
\text { Marker } \\
\text { s }\end{array}$ & $\begin{array}{c}\text { Implicat } \\
\text { ive } \\
\text { Marker } \\
\mathbf{s}\end{array}$ & $\begin{array}{c}\text { Tempor } \\
\text { al } \\
\text { Makers }\end{array}$ & $\begin{array}{c}\text { coordin } \\
\text { ate } \\
\text { Conjun } \\
\text { ction }\end{array}$ & $\begin{array}{c}\text { Subordin } \\
\text { ate } \\
\text { Conjunct } \\
\text { ions }\end{array}$ & $\begin{array}{c}\text { Adverbia } \\
\text { Is }\end{array}$ & $\begin{array}{c}\text { Prepositi } \\
\text { onal } \\
\text { Phrases }\end{array}$ & $\begin{array}{c}\text { Prepositi } \\
\text { ons }\end{array}$ \\
\hline \multirow{2}{*}{$\begin{array}{c}\text { proficie } \\
\text { ncy }\end{array}$} & $\begin{array}{c}\text { Pearson } \\
\text { Correlati } \\
\text { on }\end{array}$ & -0.29 & -0.104 & 0.155 & -0.292 & 0.31 & 0.247 & 0.142 & $0^{\text {a }}$ & 0.131 \\
\cline { 2 - 12 } & $\begin{array}{c}\text { Sig. (2- } \\
\text { tailed) }\end{array}$ & 0.883 & 0.529 & 0.422 & 0.124 & 0.875 & 0.196 & 0.463 & $0^{\text {a }}$ & 0.497 \\
\cline { 2 - 12 } & $\mathbf{N}$ & 29 & 29 & 29 & 29 & 29 & 29 & 29 & 29 & 29 \\
\hline
\end{tabular}

a Cannot be computed because at least one of the variables is constant.

The statistical results show that there are no differences between writing proficiency and different kinds of semantic and syntactic DMs. If we look at $p$-value in the third row, we find that the $p$-value is $>\alpha=0.05$, so in this level it is not significant.

The $p$-value for writing proficiency and contrastive markers is 0.883 and this value is $>\alpha=0.05$, so statistically it is not significant and there are no differences between them.

The $p$-value for writing proficiency and elaborative markers is 0.529 and this value is $>\alpha=0.05$, so statistically it is not significant and there are no differences between them.

The $p$-value for writing proficiency and implicative markers is $\mathbf{0 . 4 2 2}$ and this value is $>\alpha=0.05$, so statistically it is not significant and there are no differences between them.

The $p$-value for writing proficiency and temporal markers is 0.124 and this value is $>\alpha=0.05$, so statistically it is not significant and there are no differences between them.

The $p$-value for writing proficiency and coordinate conjunctions is 0.872 and this value is $>\alpha=0.05$, so statistically it is not significant and there are no differences between them.

The $p$-value for writing proficiency and subordinate conjunctions is 0.196 and this value is $>a=0.05$, so statistically it is not significant and there are no differences between them.

The $p$-value for writing proficiency and adverbials is 0.463 and this value is $>\alpha=0.05$, so statistically it is not significant and there are no differences between them.

The $p$-value for writing proficiency and prepositions is 0.497 and this value is $>\alpha=0.05$, so statistically it is not significant and there are no differences between them.

For clarifying and elaborating the fact that there is no significant difference between the writing proficiency and the use of different kinds of DMs, the researcher showed the scatter diagrams of writing proficiency and different kinds of DMs. 
ISSN 2348-3024

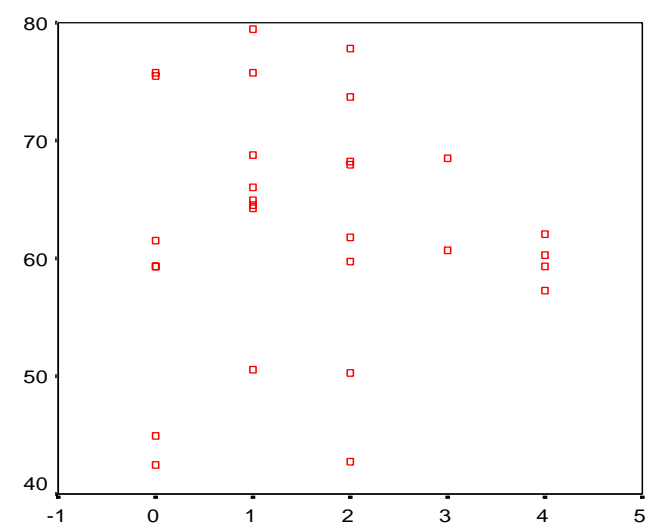

CONTRASTIVE MRKERS

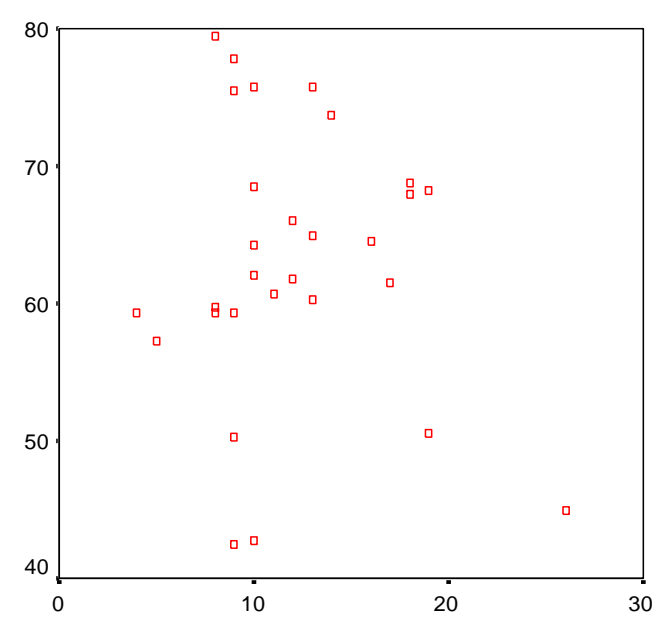

ELABORATIVE MARKERS

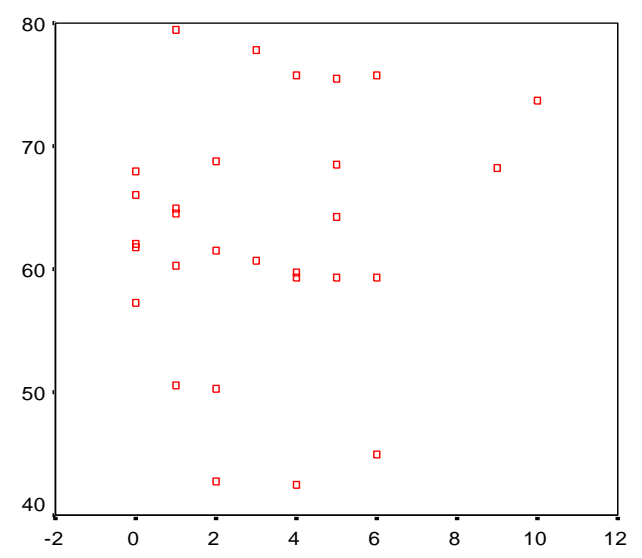

IMPLICATIVE MARKERS

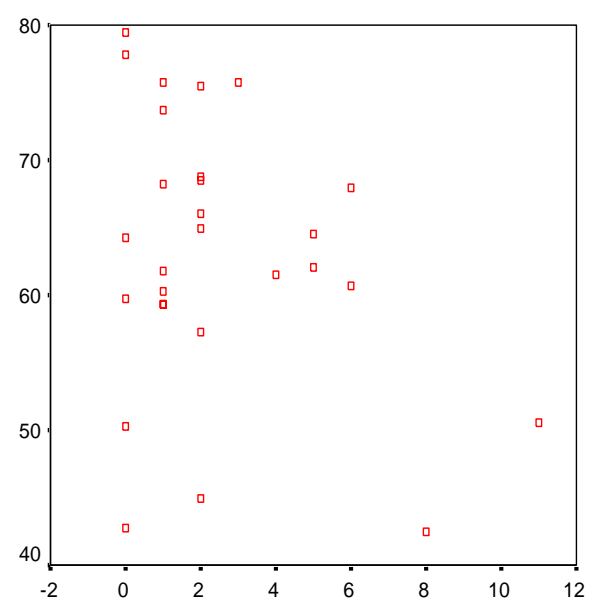

TEMPORAL MARKERS

$110 \mid \mathrm{P}$ ag e

February 15,2014 
ISSN 2348-3024

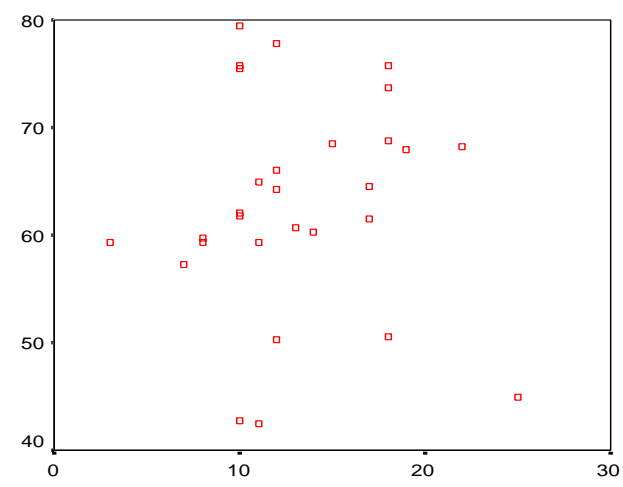

coordinate conjunctions

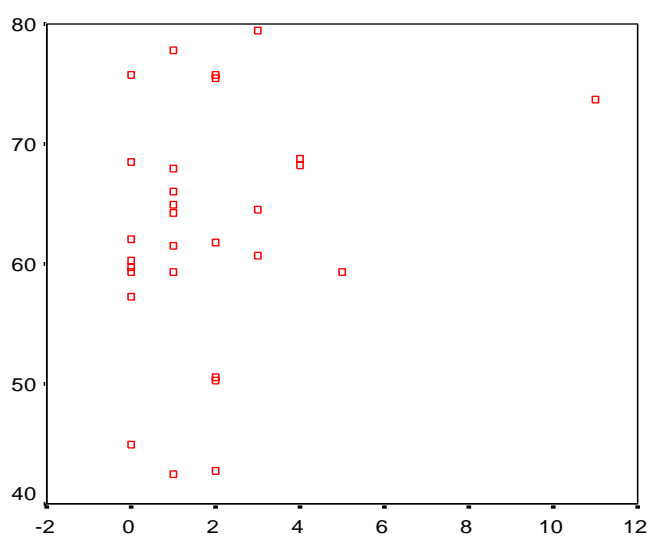

subordinate conjunctions 80 :

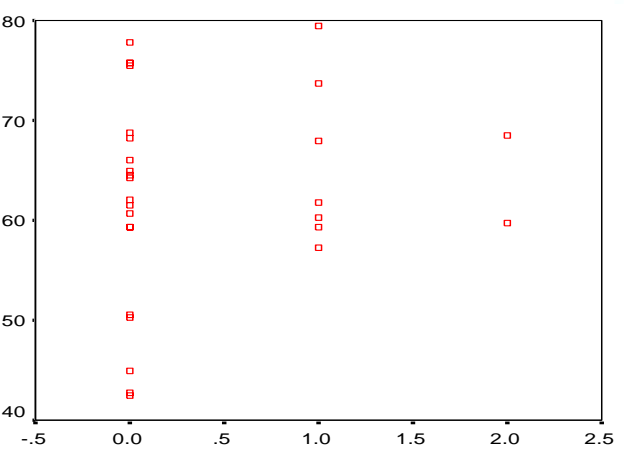

adverbials

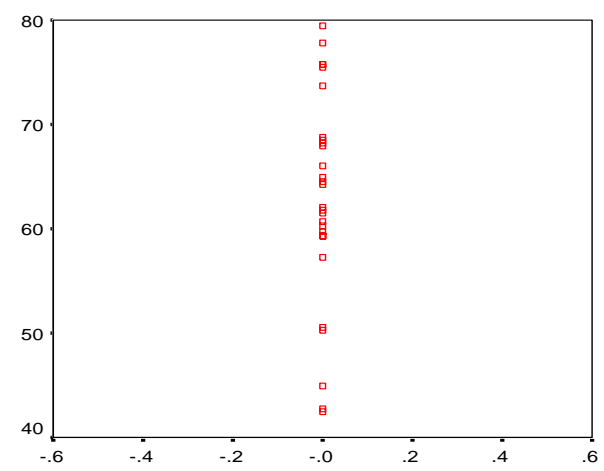

prepositional phrases

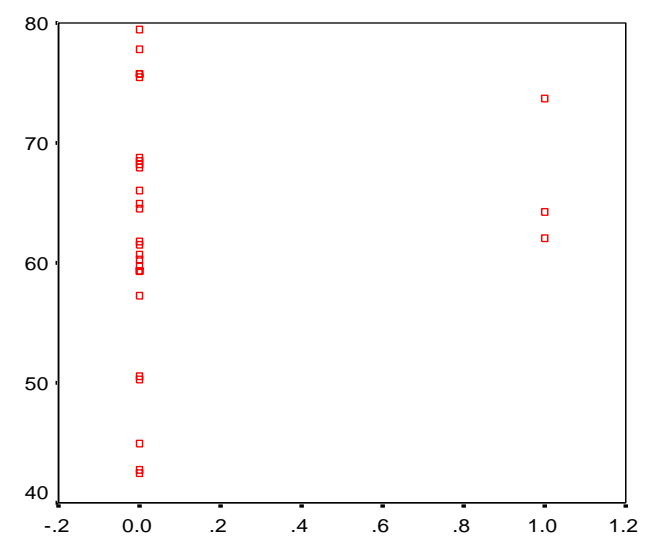

prepositions

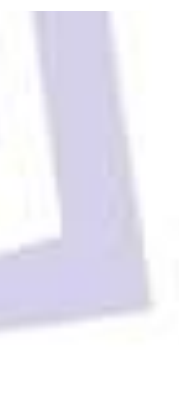

111 | Pa ge

February 15,2014 


\section{Fig.1: The scatter diagrams of writing proficiency and different kinds of DMs}

As it is given in the above Fig. there is no correlation between writing proficiency and different variables. According to Farhady et al (1994) a correlation is considered high when it is close to +1 or -1 and low when it is close to 0 .

The participant in this study used the following DMs in general but with different frequency:

Contrastive DMs: But, however, although, despite, yet, Instead of

Elaborative DMs: and, for example, or, also, in addition, for instance

Implicative DMs: based on these reasons, the other reason is that, one of the reasons that, as, because of, because, so, one reason might be that, another reason that, thus, in this situation, in this way, in this condition, in this condition for the reason of, in this way that

Temporal DMs: when, finally before, first, second, third, as soon as, then

Coordinate conjunctions DMs: and, but, so, or

Subordinate conjunctions DMs: as, if, although

Adverbials: then, still, however

Prepositional DMs: despite, instead of

But prepositional phrases DMs were the only group which was not used by any subjects. As it is italicized, these DMs (but, and, so because, when, and, as, however, instead of) extensively used by participants within each group of DMs.

Thus, findings of this study support Koczogh \& Furkó (2011) investigated the use of DMs based on gender. The results seem to contradict previous research by Holmes (2001), the research as presented in the British National Corpus, Macaulay (2002), and the research done by Croucher (2004).

From the results obtained, we can say that participants used different varieties of DMs with different frequency . It is clear that some of DMs are used more frequent than others. For example all of the subjects used Elaborative DMs and coordinate conjunction DMs extensively. The percentage of these variables revealed that Elaborative markers were the most frequently employed (62.65\%), followed by implicative markers (16.51\%), temporal markers (12.56\%), and contrastive markers (8.25\%) in the Fraser's Semantic Taxonomy of DMs and Coordinate conjunctions were the most frequently employed (85.04\%), followed by subordinate conjunctions $(11.83 \%)$, adverbials $(2.45 \%)$, prepositions $(0.66 \%)$, and prepositional phrases $(0 \%)$ in Fraser's syntactic category.

It can be concluded that the extensive use of coordinate conjunction is because there is a great overlap between this group of DMs and elaborative and contrastive DMs.

Some of the students wrote a text with excessive use of discourse markers which overshadowed the text and made it difficult to read; on the contrary, others wrote compositions without DMs. However, lack of these textual elements in their composition made the texts more difficult to read. These writers seemed too busy with constructing sentences to pay attention to the use of DMs which seem to require a deeper level of understanding.

Kubota (1998) specifically found that insufficient L2 skills account for the lack of attention to organization the use of simple text structures, ineffectiveness in connecting paragraphs, or inadequate paragraphing. Even though the students' classroom teachers may not directly teach discourse marker use, learners may be modeling that use in the classroom, and they satisfy themselves with the idea that if they use too many DMs, they are making their composition more cohesive and acceptable.

Also we noted that most participants used a certain number of discourse markers in their writing, but they are not sure what is the correct way to use them. So some mistakes or inappropriateness occur in their writing.

\section{Conclusion}

In this study, the researchers tried to find possible differences between writing proficiency and the use of different types of DMs. As it is indicated from table 4.16 there is no significant difference between these variables. That is the use of DMs is not correlated with the proficiency of participants. For example, the subject with writing proficiency of 79.5 used totally $24 \mathrm{DMs}$ (total words in essay=313) and the other subject with writing proficiency of 42.5 used 33 DMs (total words in essay 292). This fact is shown in Fig. 4.3 by scatter diagrams of different types of DMs and writing proficiency. So the second hypothesis of the study which formulated: "there is not any significant difference in the use of DMs in writing of Iranian EFL learners and their writing proficiency." is confirmed.

These findings support Lahuerta Martínez (2004) studies of the use of DMs in the expository compositions of Spanish undergraduates. The findings also confirm Jalilifar (2008) who showed that students employed DMs with different degrees of occurrence. Elaborative markers were the most frequently used. He investigated DMs in descriptive compositions of 90 Iranian students. Findings of this study are similar to Demirci and Kleiner (1997). They revealed that DMs were employed extensively by participants. However, the participants differed from each other in several respects. Although all participants made use of some DMs, some participants employed a wider range of markers than others. Some learners used certain markers extensively, while others utilized the same markers rarely if at all. Hu et al. (1982) found that 
Chinese students used more conjunctions and Australian students more lexical cohesion. In this study we found that Iranian EFL learners used Coordinate conjunctions (85.04\%) and it is high. Johns (1984) also discovered that conjuncts were overused by native speakers. Field and Yip (1992) found that Hong Kong students used more conjunctions than Australian students and they usually put all conjunctions at the beginning of the sentence. Zhang (2000) also found that Students employed in their writing a variety of cohesive devices with some categories of ties used more frequently than others.

These findings confirm Johnson (1992), Zhang (2000), but contradict Allard and Ulatowska (1991), Norment (1994) Lahuerta Martínez (2004), Jalilifar (2008).

\section{References}

Allard, L. \& Ulatowska, H. K. (1991). "Cohesion in written narrative and procedural discourse of fifth-grade children". Linguistics and Education, 3 (1), 63-79.

Bailey, K. M.. \& Brown, J. D. (1984). A categorical instrument for scoring second language writing skills. Language Learning, 34 (4), 21-38.

Croucher, S. (2004). Like, you know, and what I'm saying: A study of discourse markers frequency in extemporaneous and impromptu speaking. Retrieved April $5^{\text {th }}$ (2008), from http://cas.bethel.edu/dept/comm/nfa/journal/vol22no2-3.pdf

Demirci, M. \& Kleiner, B. (1997). "Discourse markers in second language research". Journal of Intensive English Studies, 11, 131-142.

Farhadi, H.\& Jafarpur,A.J. \&Birjandi, P.(1994). Testing Language Skills: From Theory to Practice. Tehran: the center for studying and compiling universities books in humanities (SAMT).

Field, Y. \& Yip, L. M. O. (1992). "A comparison of internal conjunctive cohesion in the English essay writing of Cantonese speakers and native speakers of English". RELC Journal 23, 1, 15-28.

Fraser, B. (2004). An account of discourse markers. In Grases, P., R. Gomez, L. Fernandez \& M. Podilla. (Eds.). Current trends in intercultural, cognitive and social pragmatics. Sevilla: Universidad de Sevilla: 13-34.

Halliday, M. \& Hasan, R. (1976). Cohesion in English. London: Longman.

Holmes. J. (2001). An Introduction to Sociolinguistics. London: Longman Group. http://www.linguistics.uiuc.edu/ggreen/discourse.pdf [20.12.2006].

Hu, Z., D. F. \& L. B. Brown (1982). "Some linguistic differences in the written English of Chinese and Australian students". Language Learning and Communication, 1, 39- 49.

Jalilifar, A. (2008). Discourse Markers in Composition Writings: The Case of Iranian Learners of English as a Foreign Language. English Language Teaching, 1(2), 114-122.

Johnson, P. (1992). "Cohesion and coherence in compositions in Maly and English language". RELC Journal, 23(2), 1 17.

Kubota, R. (1998). An investigation of LI-L2 transfer in writing among Japanese university students: Implications for contrastive rhetoric. Journal of Second Language Writing, 7, 69-100.

Koczogh, H. V. \& Furkó, B. P. (2011). Gender differences in the use of the discourse markers 'you' know and 'I mean'. Argumentum, 7, 1-18.

Lahuerta Martínez, A. C. (2004). Discourse markers in the expository writing of Spanish university students. IBÉRICA, 8 , 63-80.

Macaulay, R. (2002). You know, it depends- Vous savez, cela dépend. Journal of Pr agmatics, 6, 746-767.

McCarthy, M. \& Carter, R. A. (1994). Language As Discourse. Perspectives for Language Teaching. London: Longman.

Norment, N. (1994). "Contrastive analyses of cohesive devices in Chinese and Chinese ESL in narrative and expository written texts". Journal of Chinese Language Teaching Association, 29(1), 49-81.

Redeker, G., (1991). Review article: Linguistic markers of discourse structure. Linguistics, 29(6), 1139-1172.

Schiffrin, D. (1987). Discourse markers. Cambridge: Cambridge University Press.

Zhang, Z. (2000). "Cohesive features in the expository writing of undergraduates in two Chinese universities". Journal of RELC, 31(1), 61-95. 